\title{
Duvidar, hesitar, fracassar: anotaçóes sobre ação e suspensão em Nocturno de Chile, de Roberto Bolaño
}

Henrique Barbosa Primon

Recebido em: 5 de asosto de 2019

Aceito em: 27 de agosto de 2019
Professor e tradutor. Graduado em engenharia civil e urbana na Escola Politécnica da USP. Contato: henrique.primon@ usp.br Brasil 
PALAVRAS-CHAVE: dúvida; hesitação; fracasso; Nocturno de Chile; Roberto Bolaño.

KEYWORDS: doubt; hesitation; failure; Nocturno de Chile; Roberto Bolaño
Resumo: Este ensaio parte da presença da dúvida na fundação de tradições escritas, apontada em mitos e filosofias ancestrais da civilização ocidental, para então observar sua constância no romance Nocturno de Chile (2000), de Roberto Bolaño, enquanto motivo essencial da vida de seu narrador-personagem, o padre Urrutia/ lbacache. Suas ações e rememorações, movidas pela angústia da incerteza, mostram-se, a todo momento, suspensas e paralisadas pela tensão desestabilizante da insegurança. A dúvida que imanta o personagem irradia em todo o relato e, por si própria, é o núcleo gerador da hesitação e do fracasso, outros aspectos que suspendem a narrativa do padre Urrutia. Este ensaio almeja ainda apontar a hipótese da dúvida como topos relevante da literatura contemporânea, sugerindo uma atenção para seu estatuto de temática fundadora do homem moderno.

Abstract: This paper takes the presence of the doubt on the foundation of written traditions, as observed within ancient myths and philosophies among western civilization, as a starting point in order to observe its ubiquity in the novel Nocturno de Chile (2000), by Roberto Bolaño, and also as an essential motive for the narrator's life, the priest Urrutia/lbacache. His actions and memories, moved by the anxiety of uncertainty, are suspended and paralyzed all the time by this destabilizing tension. The doubt that informs the character radiates through the whole narrative and it is itself a corecreator of hesitation and failure, some other aspects that suspend the priest's narrative. This paper also proposes a hypothesis: the doubt as a relevant topos for contemporary literature, sussesting attention for its place as a foundational theme for the modern man. 
E se isto é assim - disse Ivan Ilitch consigo - e eu parto da vida com a consciência de que destruí tudo o que me foi dado, se náo se pode mais corrigi-lo, que fazer entáo? ${ }^{1}$ (A Morte de Ivan Ilitch, Tolstoi)

\section{DUVIDAR}

De onde vem a dúvida? A pergunta pareceria quase infantil, não fosse a resposta também pueril que levanta. "Ora, duvidamos porque duvidamos", dir-se-ia; ou, então, "duvidamos porque as aparências nos enganam.” Mesmo essa segunda tentativa de resposta, que parece refinar a dúvida, mostra-se apenas um truísmo. Quando muito, a asserção de que "duvidamos porque as aparências enganam” é apenas uma justificativa convencional.

Que as aparências enganam é uma antiga experiência da dúvida, remontando talvez até Parmênides, com sua distinção entre o caminho da doxa (opiniáo), que versava sobre a aparência cambiante das coisas aos sentidos, e o caminho da verdade, que buscava os atributos fixos do ser. Entretanto, a arqueologia da dúvida - como e por que ela nasce - é tema pouco abordado, pouco experimentado pelos estudos literários. Essa parca exploração do estatuto da dúvida contrasta com sua presença longínqua na tradição escrita. Nos primórdios da tradição judaico-cristã, no registro bíblico do Gênesis, a própria condição humana nasce justamente de uma dúvida primordial. A serpente, aproximando-se do jardim do paraíso, pergunta à

1 A fala é de Ivan Ilitch, protagonista da novela A Morte de Ivan Ilitch, ao rememorar sua vida no leito de morte. (Tolstoi, 2009, 72) 
mulher, Eva, por que os frutos de uma determinada árvore não podem ser comidos. Eva responde que foram alertados por Deus que, caso comessem daquele fruto, morreriam instantaneamente. $\mathrm{O}$ relato prossegue:

A serpente disse então à mulher: "Não, não morrereis! Mas Deus sabe que no dia em que desse fruto comerdes, vossos olhos se abrirão e vós sereis como deuses, versados no bem e no mal." A mulher viu que a árvore era boa ao apetite e formosa à vista e que essa árvore era desejável para adquirir discernimento. (Bíblia, 2002, 37)

Considerada "astuciosa", a serpente sugere uma bifurcaçấo: partindo da superfície do fenômeno, que é a observação do fruto, sua verdadeira essência pode ser tanto a letalidade determinada por Deus quanto um tipo de saber ou conhecimento, como quer fazer crer a serpente. As vias são duas: fruto é morte, segundo o Deus bíblico, ou fruto é discernimento, segundo a serpente. É a consciência dessa bifurcação - ou, nos termos de Parmênides, a existência de uma via da verdade e de outra da opiniáo - que instaura a possibilidade. Onde há possibilidade, deve haver escolha e, com ela, aparece a dúvida.

A serpente instiga um descolamento fatal: a aparência da árvore - "boa ao apetite e formosa à vista" - e a essência que seu fruto conteria - ou versar "no bem e no mal", ou matar. O descolamento entre a superfície do fenômeno e a essência de sua realidade, implantado pela serpente nessa tradição, gera a possibilidade de que um fenômeno seja seu contrário, ou que seja ainda algo distinto, de outra ordem. A possibilidade, enquanto consciência da distância entre aparência e essência, é o fundamento da experiência da dúvida. É pela consciência dessa distância que Eva, no Gênesis, vê-se imersa na dúvida e, 


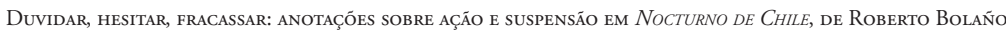

tão logo considera essa fenda mostrada pela serpente, hesita naquilo que considerava verdade.

Em que pese a origem talvez milenar dessa condiçáo autenticamente humana, a dúvida só seria alçada à categoria de imperativo humano ao longo da era moderna. Desde a máxima cartesiana, cogito ergo sum, é ela a própria fundação do ser humano contemporâneo. A dúvida fundante, entretanto, trouxe a reboque o custo, que ainda pagamos nestes fins da era moderna, de subtrair a verdade e a certeza da própria realidade. Hannah Arendt, em seu instigante e complexoThe Life of the Mind (1978), ao discutir o cogito cartesiano e as consequências do pensamento, faz esta exata observação: a dúvida, consequência imediata do pensamento, desrealiza aquilo que toca:

Thinking, however, which subjects everything it gets hold of to doubt, has no such natural, matter-of-fact relation to reality. It was thought - Descartes' reflection on the meaning of certain scientific discoveries - that destroyed his common-sense trust in reality [...] (Arendt, 1978, 52. Grifo da autora.).

De onde vem a dúvida? Por hora descrevemos, de forma breve e conceitual, que a dúvida parece surgir da consideração da possibilidade, dos percursos possíveis do fenômeno até sua essência. Entretanto, na concreção da vida e da arte, a questáo persiste.

Em Nocturno de Chile (2000), romance-paródia² de Roberto Bolaño, essa pergunta reverbera com uma constância latente e enigmática, multiplicando-

2 Linda Hutcheon, teórica canadense do pós-modernismo, em seu A Poetics of Postmodernism: History, Theory, Fiction (1988), define efeitos da paródia do trabalho de arte pós-moderno que se alinham à paródia do romance de Bolaño: "[...] postmodernist [parodic] art offers a new model for mapping the borderland between art and the world, a model that works from a position within 
se e infiltrando-se em todas as fendas da vida do narrador-memorialista, o padre Sebastián Urrutia Lacroix, que utiliza o pseudônimo de H. Ibacache para exercer sua outra atividade, a de crítico literário.

A matéria do romance é múltipla. O confronto e o entrecruzamentto de rememoraçóes e experiências sutilmente conexas redundam na construção de um enredo que, mesmo relativamente conciso, abunda em temas caros à literatura e aos estudos literários. O narrador se defronta reiteradamente com o jovem envelhecido, um duplo misterioso e particular, que entra e sai do relato em momentos precisos. Outros temas sobressaem: a alienação consciente e o exilio voluntário, culposos na consciência do narrador-personagem; o ressentimento que assoma repetidamente; a grave inflexão do remorso, que o narrador atinge ao fim da vida; o fracasso, em muitos níveis: do escritor e do intelectual, do padre, da vida de um homem, de sua redenção; a memória dúbia e incerta.

O epíteto de romance "paródia" que utilizamos aqui não é fortuito. Uma paródia contém o pastiche de um referente. Em toda paródia subjaz um simulacro cômico-irônico, que suspende (e, não raro, escarnece e nega) a legitimidade ou a verdade daquilo que é emulado. É justamente por instaurar a dúvida que esse romance pode parodiar figuras da história recente chilena. Muitos dos personagens apontam para essa remissão paródica: o padre

both and yet not totally within either, a model that is profoundly implicated in, yet still capable of criticizing, that which it seeks to describe. "(Hutcheon, 1988, 23) Embora náo tratemos aqui da inserção do romance e da obra de Bolańo no chamado pós-modernismo, a aderência de Nocturno de Chile ao aspecto paródico é clara, precisamente por borrar "a fronteira entre mundo e arte" $\mathrm{e}$ por criticar aquilo que descreve e que implica. A essa característica do romance de Bolaño, que sugerimos aqui en passant, caberia maior aprofundamento, o que fugiria, entretanto, de nosso escopo. 


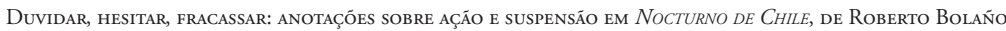

Urrutia/crítico Ibacache remete diretamente a José Miguel Ibañez Langlois (1936-), padre e crítico literário chileno; o pseudônimo Farewell remete ao também crítico chileno Hernán Diaz Arrieta (1891-1984), que escrevia sob o pseudônimo de Alone ${ }^{3}$; outros personagens e outras cenas também remetem diretamente a pessoas e fatos históricos. Outra remissáo paródica, mais abstrata, diz respeito ao meio literário, à institucionalidade das letras chilenas, com suas convençóes e valoraçóes não raro arbitrárias, volúveis e, pior, deliberadamente alienadas. Também nesse sentido, as incursōes paródicas e irônicas são muitas. É especialmente (tragi)cômico o momento em que Urrutia/Ibacache, quando a vitória de Allende, primeiro, e depois a iminência do golpe militar causam furor nas ruas de Santiago, isola-se e retira-se: "Que sea lo que Dios quiera, me dije. Yo voy a releer los griegos." (Bolaño, 2000, 97). O narrador ainda faz um curto mas emblemático relato de sua arbitrariedade enquanto crítico literário, ao confessar sua falsidade na resenha do livro Palomita Blanca: "[...] Lafourcade publió Palomita Blanca y yo le hice una buena crítica, casi una glosa triunfal, aunque en el fondo sabía que era una novelita que no valía nada" (Bolaño, 2000, 97-8). ${ }^{4}$

3 A remissão dos personagens do romance a figuras históricas - Urrutia remetendo a José Miguel Ibañez, Farewell, a Hernán Diaz Arrieta - é lembrada pela professora Laura Hosiasson, em "La voz del outro y sus proyecciones" (Hosiasson, 2017, 30).

4 Laura Hosiasson, em seu "La voz del otro y sus proyecciones en Bolaño", diz de Nocturno de Chile que se trata de "novela en que se propondrá una reflexión sombría del papel de la intelectualidad letrada en la historia de la dictadura chilena” (Hosiasson, 2017, 30). Os dois assuntos, aqui apenas apontados - a crítica irônica à postura de figuras históricas supostamente coniventes com o regime ditatorial chileno, além da paródia sarcástica ao chamado meio literário -, mesmo que instigantes, não serão especificamente explorados neste trabalho. 
Tanto o espectro de temas que propusemos quanto essa remissão crítica à história estão radicados em um narrador que, essencialmente, duvida de suas próprias açôes e também de suas inaçôes. A dúvida ética, embuste onipresente de toda açấo; a dúvida da lembrança, armadilha da legitimidade da memória; a dúvida da identidade, que acompanha a tortuosa indeterminaçáo do ser humano pelos meandros do que poderia ter sido. E, talvez a mais contraditória, marcante e inevitável: a dúvida a posteriori, com a consciência torturante dos verbos e das modalizaçóes não factivas. ${ }^{5}$ Por que o padre Urrutia/Ibacache se ressente? Como ela se torna o fundamento de uma vida? Por que ela não se transmuta em ação?

O romance transcorre sob a coerção veloz da ansiedade, que se produz, ela também, pela profusão de dúvidas. Dúvida da memória, dúvida moral, dúvida identitária. E, ao fim, uma aflitiva dúvida vital: foi um fracasso?

A pletora de experiências e rememoraçōes aponta de forma centrífuga para uma desordem irrelacional, um quase delírio de rememória na vida de Urrutia/Ibacache. A unidade do romance e da vida do personagem tornamse, assim, de difícil apreensão. Este ensaio pretende sugerir que a vida de Urrutia/Ibacache está permeada e centrada por uma consciência trágica: a ubiquidade do fracasso. Também almejamos descrever como a consciência

5 George Steiner, em Grammars of creation (1990), observa a especificidade humana das modalizaçóes e dos contrafactuais, as formas gramaticais mais poderosas na manifestação da dúvida. O homem é, segundo o grande crítico, o único que pode "alterar seu mundo pelo recurso às orações 'se...”": "the ability to discuss possible events on the day after one's funeral or in stellar space a million years hence, looks to be specific to homo sapiens. As does the use of subjunctive and of counter-factual modes which are themselves kindred, as it were, to future tenses. It is only man, so far as we can conceive, who has the means of altering his world by resort to "if"-clauses". (Steiner, 1990, 6) 


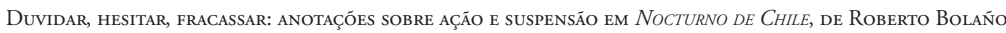

trágica do fracasso tem origem em outro traço fundamental deste narrador: o duvidar, com seu correlato imediato, a hesitação. ${ }^{6}$

\section{HESITAR}

A recorrência de alusóes a Dante Alighieri aponta para a particularidade do estatuto moral em que o padre se insere. O Dante peregrino da Divina Comédia (2016 [1472]), logo no terceiro canto do Inferno, ainda diante dos portôes e portanto antes de adentrar o reino "daqueles que perderam toda esperança”, pergunta a seu guia, Virgílio:

- Mestre, o que é isso que estou ouvindo? E que gentes são estas cuja dor parece abatê-las?

Ele respondeu:

- Esta triste condição é daqueles cujas almas vivem sem infâmia ou honra. No meio delas está o coro de anjos que nem se rebelaram nem foram fiéis a Deus, que nem foram fiéis a si mesmos. Os ceús os expulsaram para não se diminuírem com sua presença, nem o profundo Inferno os recebe, como recebe os anjos rebeldes que alguma glória ao menos tiveram. [...] Eles nem têm esperança de morrer. Tão obscura e mesquinha foi sua vida que invejam qualquer outro destino diferente do deles. (Alighieri, 2016, 38. Grifos nossos.)

Esse trecho da Comédia alude às almas que sequer foram condenadas. A tradição crítica rotula esse espaço de limbo, lugar dos que foram rejeitados

6 Inserimo-nos aqui no domínio do ensaio da forma proposta por Luiz Costa Lima; o caráter ensaístico deste texto, como é inerente em todo ensaio crítico-interpretativo, tem o objetivo não de resolver uma questáo, mas antes de colocá-la e precisar seus termos: "É ele [o ensaio] menos um meio por onde circulam ideias do que o meio em que se formulam questôes" (Lima, 2005, 99). 
tanto pelo céu como pelo inferno, um não-lugar destinado aos pusilânimes (os fracos de alma, no sentido da etimologia greco-latina). O limbo é um não-lugar ético; abriga os que não foram agentes, aqueles que não foram autores nem mesmo de si.

As passagens assinaladas neste trecho de Dante parecem revelar uma etiologia do caráter de Ibacache em três aspectos. O limbo é o lugar reservado às almas triplamente inertes: não agiram nem segundo uma bondade divina, nem segunda uma rebeldia "diabólica”, nem segundo si mesmos.

No primeiro aspecto, então, o limbo da Comédia é ocupado pelos que não foram fiéis a Deus. Em Nocturno de Chile, paralelamente, Urrutia fracassa como padre - pela mesquinharia, soberba e prepotência em que ele se surpreende por vezes, como durante uma caminhada pela fazenda de Farewell, ao visitar uma casa humilde de camponeses: "Sentí miedo y asco" (Bolaño, 2000, 20). Mais sintomático ainda que esses momentos é a própria menção rarefeita ao ofício de padre, apenas poucas vezes lembrada no relato.

Os habitantes do limbo são também aqueles que não se rebelaram. Urrutia suspende suas rebeliôes, mesmo se elas parecem urgentes. Quando dá aulas de marxismo ao general Pinochet, Urrutia insere-se de forma conivente, e até mesmo quase amigável, em um regime ditatorial. A referida cena contém, logo antes da primeira aula, um embate de consciência característico de mais essa ação suspensa. $\mathrm{O}$ irresoluto padre Ibacache hesita, e ao fim permanece estagnado:

Ganas me dieron de tirar la taza contra las impolutas paredes, ganas me dieron de sentarme con la taza entre las rodillas y llorar, ganas me dieron de 


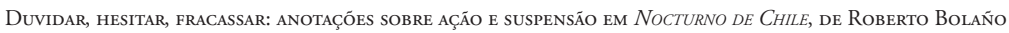

hacerme pequeño y sumergirme en la infusión tibia y nadar hasta el fondo, donde descansaban como grandes trozos de diamantes los granos de azúcar. Permanecí hierático, inexpresivo. Puse cara de aburrimiento. (Bolaño, 2000, 108. Grifos nossos.)

O limbo dantesco é, enfim, o lugar daqueles que "nem foram fiéis a si mesmos". Também nesse terceiro aspecto, o padre é candidato perfeito ao não-lugar ético da Divina Comédia. A infidelidade a si próprio é um dos seus aspectos mais emblemáticos. É infiel a sua condição de padre; infiel ao crítico literário independente. Incapaz, ainda, de ser fiel a seu ímpeto, algo vaidoso, de ser o grande poeta canônico Urrutia Lacroix. E, talvez a maior infidelidade dirigida a si próprio: é incapaz de se rebelar contra suas próprias falsidades. Porque as funçóes de padre e crítico, ao longo do relato, parecem se tornar apêndices performativos que o narrador já não deseja, papéis societários já totalmente esvaziados e quase ao relento. Mesmo assim, não age.

Essa abstenção de ação que Urrutia/Ibacache manifesta, abstenção própria da postura do observador, do julgador, do crítico, é fruto da própria experiência de dúvida que o narrador infunde em sua vida e em seu relato. A dúvida subjacente aparece em seu aspecto mais claro e paradoxalmente mais sutil: a dúvida enquanto inação.

O produto imediato da dúvida é a hesitação, oscilação inerte daquele que duvida. A dúvida é uma suspensão. Suspende a ação para duvidá-la. A dúvida gera, no lugar da ação, o instante indefinido da hesitação. E a dúvida suspende não apenas a ação presente, mas até mesmo o caráter de 
realidade consumada do passado; póe em xeque náo apenas o suporte e a estância verdadeira do presente; mas também embaralha e, no limite, achata toda possibilidade futura de ação. É precisamente o que Hannah Arendt nota: a dúvida póe a descoberto um engano, mas nada descobre para além disso: "The uncovering destroys a deception; it does not discover anything authentically appearing" (Arendt, 1978, 39).

A incerteza de uma vida mal vivida é uma vida que pareceu ter sido reta mas que se revela, no momento final, falseada. A insegurança de haver realizado uma atividade paradoxalmente marginal e soberba, a do crítico que muito ambicionava mas cujas açóes foram, de fato, a passividade do observadorjulgador que não toma parte, que se esquiva de agir, que se abstém de ser o escritor ou de ser a voz de resistência e de denúncia; e, ainda, a incerteza da própria função do escritor e do crítico, do narrador-escritor que ele é, que escreve um relato que procura certa absolvição, mas que ainda não é uma ação; uma confissão de fracasso, sem perspectiva de redenção.

A dúvida parece anterior à experiência deste narrador. É tão constitutiva da vida que a antecede. A dúvida infunde a hesitação e deixa ver, à distância, a contingência do fracasso. $\mathrm{O}$ êxito está muito longe de Ibacache. $\mathrm{O}$ padre, que se tornou o célebre crítico que gostaria de ser, aparece em poucas e escorregadias passagens; só parece ter pouca e duvidosa relevância para o narrador. Crítico de sucesso é outra posição insustentável pela rememoração, uma instabilidade instaurada pela dúvida. Uma aparência que não pode ser.

No entanto, a essência ou as essências que busca esse narrador memorialista também são postas em dúvida. Ele é: o padre que queria ser? O poeta 
canônico que planejava em segredo se tornar? O crítico que se espelhou em Farewell? Um homem conscientemente relapso que se permitiu ver uma ditadura e abster-se?

\section{3. fracassar}

A dúvida é uma autossabotagem. Aquele que duvida retira-se do mundo. E retira-se de si próprio. A vida, duvidada, deixa de ser instância empírica do mundo e torna-se hipótese. O pensamento, que sempre duvida, tornase princípio desordenador para Urrutia/Ibaccache, e redunda em uma consciência autodestruidora de sua própria base, qual seja, o decurso da própria vida. A dúvida imanta a vida, para então sabotá-la. É a consciência do fracasso.

"[...] [L]a vida es una sucesión de equívocos que nos conducen a la verdad final, la única verdad" (Bolaño, 2000, 13), diz o padre Urrutia logo no início de seu relato. Essa asserção, em alguma medida, já anuncia a sentença de sua vida. Suas açóes e inaçóes, suas palavras e silêncios estão contaminados, logo de partida, pela consciência do erro fatal.

O pintor guatemalteco e seu quadro da Cidade do México, em cujo sótão conversam um Salvador Reyes e um Ernst Jünger ficcionais, prefiguram essa consciência da frustração pessoal: "el cuadro era la aceptación de una derrota, no la derrota de Paris ni la derrota de la cultura europea briosamente dispuesta a incinerarse a sí misma ni la derrota política de unos ideales que el pintor vagamente compartía, sino la derrota de él mismo, 
un guatemalteco sin fama ni fortuna" (Bolaño, 2000, 48. Grifos nossos.). $\mathrm{O}$ pintor guatemalteco é o artista que ousou a verdade de sua expressão: a derrota de si próprio, o apagamento de sua história e de sua vida em favor da autenticidade de sua expressáo. $O$ paradoxo é que mesmo sua realizaçáo artística autêntica constitui uma derrota cenográfica, e expressa ainda uma "derrota dele mesmo". O guatemalteco permanece silencioso ante os colóquios dos escritores que o frequentam; está incógnito, distante da história e da vida, talvez justamente por já tê-la intuído e realizado com exata plenitude em sua pintura.

O fracasso, para o narrador-personagem, percorre ainda diversos cenários, tangencia outros personagens, encampa diversos atos, colore diversos matizes de sua própria consciência cambaleante. Parece haver dois finais trágicos, dois fracassos correlatos nessa pergunta, que são, por sua vez, constataçôes aterradoras: a primeira, da descoberta de uma identidade náo realizada, a do jovem envelhecido; a segunda, o apelo gritante de uma vida que se descobriu, enfim, falsa. Descobrir-se um jovem envelhecido é admitir-se uma potência que náo se realizou; uma vontade que nunca chegou a ser ato e que, portanto, agoniza; a bifurcaçáo náo percorrida de uma vereda borgeana, que se sugere, mesmo assim, ter sido a verdadeira. "Un otro entonces que no es sino el otro de sí mismo, también él un escritor o más bien el escritor que el cura pudo ser y no fue, es decir el responsable por una literatura corajuda y honesta" (Rojo, 2016, 177).

"El joven envejecido siempre ha estado solo y yo siempre he estado con la historia" (Bolańo, 2000, 148), diz o padre Ibacache. O jovem envelhecido, 


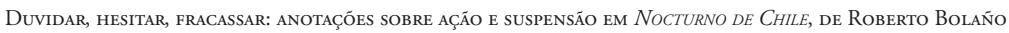

talvez porque terrivelmente verdadeiro, sempre esteve solitário, tão esquivo e marginal quanto o pintor guatemalteco, e por isso tão original e tão temerário. A vida do padre Ibacache sempre esteve na história: caminhou junto a ela, a seus grandes nomes e movimentos; sempre buscou, de muitas formas, a gregariedade da fazenda de Farewell, das propostas de Odeim e Oido, das festas de Canales. O medo de olhar e de percorrer a vida do jovem envelhecido é, também ele, um medo instaurado pela dúvida: teria o padre suportado uma existência arredia e marginal, mesmo que mais verdadeira, como o pintor guatemalteco? Teria Ibacache suportado essa existência solitária, essa existência desaparecida, mas autêntica, que sugere a todo momento o jovem envelhecido? Essas dúvidas e suas implicaçóes - a consciência do medo, da fraqueza, da inautenticidade da vida vivida - são, mais uma vez, a consciência maior do fracasso.

Ibacache não quis desaparecer - não teve a coragem, como o guatemalteco, de ser autenticamente um autor, e ao fim deixar sua personalidade evadir, deixar sua figura pública se esvair para deixar aparecer a obra, deixar o júri do crítico para correr o risco da autenticidade - que é, fatalmente, o risco de outro insucesso. No conto "A arte de desaparecer", do livro Suicidios Ejemplares (2015 [1991]) de Enrique Vila-Matas, o protagonista Anatol é um escritor que se recusa a ser publicado em vida: lega postumamente um baú com seus escritos. "[Anatol] Pensou: a obrigação do autor é desaparecer. [...] Pensou: há pessoas que sempre ficam bem em outro lugar” (Vila-Matas, 2015, 74). A situação de Anatol neste conto vilamatasiano é semelhante à do pintor guatemalteco de Bolaño; semelhante também à posição solitária 
e periférica do jovem envelhecido, semelhante talvez à marginalidade do próprio Bolaño em relação ao "sistema", à institucionalidade literária chilena. A obrigação do autor, para o personagem Anatol, é desaparecer, ficar em outro lugar. O narrador de Nocturno de Chile não consegue deixar a si próprio; não consegue deixar de ser o padre Urrutia, ou o crítico Ibacache, ou o professor de Pinochet, ou o frequentador das festas de María Canales. Não consegue abandonar as centralidades que ocupa, por duvidosas e hesitantes e fracassadas que sejam. Para ser verdadeiramente um autor, para ser verdadeiramente "responsable de sus actos y también de sus palabras e incluso de sus silencios" (Bolaño, 2000, 11), esse narrador talvez tivesse que "desaparecer": encontrar sua própria margem da história para ser, enfim, autêntico.

O pintor guatemalteco e o jovem envelhecido se aproximam em suas solidôes e, especialmente, em suas invisibilidades. Enquanto Salvador Reyes e Ernst Jünger - a "história", o correr dos fatos centrais - conversam, o pintor guatemalteco parece ser apenas parte do cenário. Ele, como o jovem, como aliás o contexto político que se desdobra em todo o romance, estão postos em uma periferia, observados de uma distância "segura". O distanciamento, imposto pelo narrador Urrutia, tem uma finalidade sutil e inescapável: evitar a erupção da instabilidade que elas representam.

Urrutia oscila entre uma ação, enquanto ética e vitalmente autêntica, e sua suspensão. Há nele um movimento pendular, que oscila entre o momento da dúvida e a hesitaçáo dela decorrente. A culminação fatal é a da constataçấo de um fracasso vital e irrevogável e, por isso, trágico. 


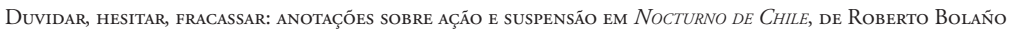

\section{IRREVOCABILIDADE DO FRACASSO}

Afinal, de onde vem a dúvida? Para o padre Sebastián Urrutia Langlois, a dúvida entra em cena junto com o jovem envelhecido. Ele figura, a um primeiro olhar, a alteridade, que aterroriza pela aparição insuspeitada em momentos decisivos. Para além de ser a voz de um outro, como sugeriu Laura Hosiasson a propósito da obra de Bolaño, o jovem envelhecido é a figuração da própria possibilidade, a ponta solta de um desdobramento fatal do que poderia ter sido uma vida. Ele é um duplo particular na literatura, por encarnar o contrafactual e martelar com insistência, no agonizante padre Urrutia, o que ele poderia ter sido. Esse duplo é, paradoxalmente, a perversão satírica de uma realidade - uma vida - já consumada. O jovem envelhecido concentra, poderíamos dizer, a dúvida desestabilizadora, concretizada no tecido da rememoração de Urrutia. O epítome da derrota encontra-se neste jovem, em sua aparição insistente. "¿Esto es el verdadero, el gran terror, ser yo el joven envejecido que grita sin que nadie lo escuche?" (Bolaño, 2000, 49). Essa pergunta, dúvida final do narrador, apresenta a perplexidade daquele que se descobre em uma verdade instável. Um duplo do outro, duplo do que poderia ter sido, duplo de uma autenticidade agora impossível e irrevogável.

Uma das grandes tragédias do "fracasso de uma vida" na literatura moderna é A Morte de Ivan Ilitch, de Liev Tolstoi. Nocturno de Chile está próximo dessa novela. Ibacache e Ivan Ilitch agonizam em seus momentos finais, enquanto suas memórias são tomadas pelo arrependimento e por uma angústia: o fracasso de suas vidas é irrevogável. "[...] [T]udo aquilo era 
o que não devia ser, mas um embuste horrível, descomunal, que ocultava tanto a vida como a morte." (Tolstoi, 2009, 72), diz Ivan Ilitch ao encarar os arredores de seu quarto de moribundo, a vida que construiu mas que "não devia ser". Ivan Ilitch, como o padre Ibacache, arrepende-se da vereda tomada, que se revelou falsa.

Desde a primeira mulher bíblica, que duvidou das palavras de Javé, até a dúvida metódica que Descartes assumiria, ${ }^{7}$ estado permanente do homem moderno e de sua literatura, o duvidar tem sido o risco do homem: perder suas certezas e, com elas, perder a própria realidade e, ainda, qualquer ilusão de verdade. "A ingenuidade e a inocência do espírito se dissolvem no ácido corrosivo da dúvida. O clima de autenticidade se perde irrevogavelmente" (Flusser, 2018, 9). Uma verdade, ou, antes, uma certeza é o que perdeu o padre Ibacache, ao encarar a rememoração, ao encarar o jovem envelhecido em busca, este sim, de verdade. E a recordação de suas dúvidas, diferentemente do que almejava no início, uma expiação de culpas e uma reafirmação da vida, produziu seu contrário: a derrocada do inteletual, do padre, do crítico, do escritor potencial. Ao fim de tantas quedas, desse anti-herói emergiu um renunciador.

\section{REFERÊNCIAS BibLIOGRÁFICAS}

Alighieri, Dante. A Divina Comédia. Tradução em prosa de Eugênio Vinci de Moraes. São Paulo: Editora L\&PM Pocket, 2016 [1472].

7 “ [...] Descartes parte da única coisa que tem: de sua própria dúvida, de sua radical incerteza. É preciso pôr em dúvida todas as coisas, pelo menos uma vez na vida [...]” (Marías, 2004, 231). 


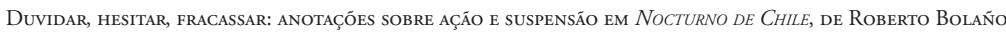

Arendt, Hannah. The Life of the Mind. Orlando: Harcourt Inc., 1978.

Bíblia. A Bíblia de Jerusalém. São Paulo: Editora Paulus, 2002.

Bolaño, Roberto. Nocturno de Chile. Barcelona: Anagrama, 2000.

Flusser, Vilém. Da Dúvida. São Paulo: É Realizações, 2018.

Hosiasson, Laura Janina. La voz del otro y sus proyecciones en Bolaño. Leiden: Koninklijke Brill Nv, 2017. 124-35.

Hutcheon, Linda. A Poetics of Postmodernism: History, Theory, Fiction. New York: Routledge, 1988.

Lima, Luiz Costa. Limites da voz (Montaigne, Schlegel, Kafka). Rio de Janeiro: Topbooks, 2005.

Marías, Julián. História da filosofia. Sáo Paulo: Martins Fontes, 2004.

Rojo, Grinor. El ridículo espantoso (además de chileno) em Nocturno de Chile. In: Las novelas de la dictadura y postdictadura chilena: Quince ensayos críticos. Volumen II. Santiago de Chile: LOM Ediciones, 2016.

Steiner, George. Grammars of creation. New York: Open Road, 1990.

Tolstoi, Liev. A morte de Ivan Illitch. Trad. Boris Schnaiderman. São Paulo: Editora 34, 2009.

Vila-Matas, Enrique. Suicídios Exemplares. Barcelona: Debolsillo, 2015 [1991]. 62-74. 